\title{
Thermal instability of the tetragonally distorted structure of copper-iron materials
}

\section{J. Darul}

Faculty of Chemistry, Adam Mickiewicz University, Grunwaldzka 6, PL-60780 Poznań, Poland jola@amu.edu.pl

Keywords: $\mathrm{CuFe}_{2} \mathrm{O}_{4}$, powder diffraction, structural transition

\begin{abstract}
Polycrystalline $\mathrm{CuFe}_{2} \mathrm{O}_{4}$ samples have been successfully prepared using a simple combustion method starting from citrate-nitrate precursors. All the ferrite samples studied were prepared at the same temperatures $\left(300,600,900^{\circ} \mathrm{C}\right)$, but one series was slowly cooled from $900^{\circ} \mathrm{C}$ to room temperature, and another was quenched in solid $\mathrm{CO}_{2}$. The nature of the structural transition in inverse spinels has been investigated by the synchrotron XRD technique. Slowly cooled samples are subjected to a diffusionless order-disorder transformation, due to the modified of the orientation of the Jahn-Teller distortions, and to the migration of $\mathrm{Cu}^{2+}$ ions from octahedral to tetrahedral sites This phenomenon transforms the tetragonally distorted spinel structure $\left(F 4_{1} / d d m\right)$ into a cubic lattice $(F d \overline{3} m)$. It occurs at temperatures from $\sim 360^{\circ} \mathrm{C}$ to $\sim 420^{\circ} \mathrm{C}$.
\end{abstract}

\section{Introduction}

Copper ferrite is known to exist in tetragonal and cubic structure. Since $\mathrm{Cu}^{2+}$ is a Jahn-Teller ion (JT), it gives the anomalous favorable properties and also exhibits phase transition from tetragonal to cubic, depending on the temperature. The JT transition is argued to be orderdisorder in character, but its exact nature is still not fully understood [1-4]. $\mathrm{CuFe}_{2} \mathrm{O}_{4}$ can be described as a cubic close-packed arrangement of oxygen ions, with $\mathrm{Cu}^{2+}$ and $\mathrm{Fe}^{3+}$ ions at two different crystallographic sites. From a structural standpoint, the formula unit of stoichiometric ferrite can be written as: $\left(\mathrm{Cu}_{\mathrm{x}}{ }^{2+} \mathrm{Fe}_{1-\mathrm{x}}{ }^{3+}\right)_{\mathrm{A}}\left[\mathrm{Cu}_{1-\mathrm{x}}{ }^{2+} \mathrm{Fe}_{1+\mathrm{x}}{ }^{3+}\right]_{\mathrm{B}} \mathrm{O}_{4}$, where (A) denotes tetrahedral sites, [B] represents octahedral sites [2-3]. The parameter of inversion, $\mathrm{x}$, is equal to 0 for inversion spinels, and to 1 , when the spinel is normal. The temperature of the orderdisorder transformation depend on the content of octahedral cupric ions and on the nonstoichiometry [5]. When the spinel is synthesized using classical ceramic technologies (sufficiently high temperature treatment of the initial oxides of the metal cations) with strict stoichiometry, it has a tetragonal structure of hausmannite type with crystal cell parameters $a$ $=8.20 \AA$ and $c=8.60 \AA ; c / a \sim 1.05$. The $c / a$ ratio can be changed via decreasing the copper concentration, or alternatively by heat treatment temperature and cooling rate [2]. Part of the 
$\mathrm{Cu}^{2+}$ ions can be frozen in tetrahedral sites when the ferrites are quenched in air from above $400^{\circ} \mathrm{C}$. The resulting ferrites show a smaller tetragonal distortion since a great proportion of the cupric ions are located on tetrahedral sites. Moreover, quenching treatments in air from temperature higher than $750^{\circ} \mathrm{C}$ lead to the formation of oxygen-deficient spinel ferrites, the nonstoichiometry arising from the reduction of some $\mathrm{Cu}^{2+}$ ions to $\mathrm{Cu}^{+}$ions [2, 6-7]. Some authors [2-3] consider that the $\mathrm{Cu}^{+}$ions are located in the intersitial sites (i.e., sites normally not occupied in the spinel structure). Recently, it has been found, that $\mathrm{Cu}$-ferrite films can be stabilized in either tetragonal or cubic phase even at room temperature depending on deposition conditions and post-deposition heat treatment; the samples annealed in air at high temperatures $\left(>800^{\circ} \mathrm{C}\right)$ and slowly cooled to room temperature were tetragonal, while those rapidly quenched in liquid nitrogen were cubic [8-9].

In this work, bulk copper ferrites samples were prepared by a simple combustion method using citrate-nitrate precursors. A citrate process as an alternative synthesis route has been successfully employed to synthesize such materials with improved properties for specific applications, such as magnetic powder for massive storage devices [10].

\section{Experimental details}

Powder samples with nominal composition $\mathrm{CuFe}_{2} \mathrm{O}_{4}$ were prepared by the combustion method. The stoichiometric quantities of starting materials, viz., $\mathrm{Cu}\left(\mathrm{NO}_{3}\right)_{2} \cdot 6 \mathrm{H}_{2} \mathrm{O}$, $\mathrm{Fe}\left(\mathrm{NO}_{3}\right)_{3} \cdot 9 \mathrm{H}_{2} \mathrm{O}$, (Merck) and $\mathrm{C}_{6} \mathrm{H}_{8} \mathrm{O}_{7} \cdot \mathrm{H}_{2} \mathrm{O}$, were dissolved in distilled water. The mixed citrate-nitrate solution was heated at $120^{\circ} \mathrm{C}$, with continuous stirring. After the evaporation of excess of water, a highly viscous gel was obtained. Ultimately, the powder was sintered in air at different temperatures $\left(300,600,900^{\circ} \mathrm{C}\right)$ for $5 \mathrm{~h}$. After heating, the preparations were either cooled slowly (SC) to room temperature or rapidly quenched (QC) in solid $\mathrm{CO}_{2}$. The compounds formation and crystallinity of the materials were identified by XRD patterns, which were recorded on a Bruker D8 Advance diffractometer, with $\mathrm{CuK} \alpha$ radiation. Finally, investigations on the temperature phase transition for product formed as a result of slow cooling of $\mathrm{CuFe}_{2} \mathrm{O}_{4}$ sample were carried out at the synchrotron beamline B2 at HASYLAB (DESY, Hamburg). The diffractometer was equipped with capillary furnace (STOE) and the on-site readable image-plate detector OBI. The polycrystalline samples placed in quartz capillaries of diameter $0.3 \mathrm{~mm}$ were heated and cooled at the temperature range from RT to $500^{\circ} \mathrm{C}$. The wavelength, determined by calibration using a NIST silicon standard, was $0.493421 \AA$. Analysis of the XRD data was undertaken with a full-pattern fitting procedure based on the Rietveld method. Structure refinement was performed using FullProf program [11].

\section{Results and discussion}

The XRD studies show that the slow cooled and quenched in solid $\mathrm{CO}_{2}$ samples displayed different thermal behavior (figure 1). In spite of the fact that a quench cooling process usually leads to the cubic structure of $\mathrm{CuFe}_{2} \mathrm{O}_{4}[2-3,12]$, from structural analysis results based on the powder diffraction data we confirmed that the rapidly quenched sample showed a dominant cubic phase $(76.4 \%)$ with a minor tetragonal component $(23.6 \%)$. The slowly cooled sample crystallizes in the tetragonal system and at room temperature it could be indexed as a single-phase tetragonal spinel with space group $I 4_{1} /$ amd. The unit cell with lattice constants 
$a=5.8111(5) \AA$ and $\mathrm{c}=8.6888(9) \AA$ consists of four $\mathrm{CuFe}_{2} \mathrm{O}_{4}$ units. It is, however, much more informative to consider the crystal lattice as a tetragonally distorted spinel structure with the non-standard face-centred space group $F 4_{1} / d d m$. In that case the unit cell is doubled, with $a_{\mathrm{s}}$ $=8.2387(5) \AA$ and $c / a_{s}=1.055$, containing eight $\mathrm{CuFe}_{2} \mathrm{O}_{4}$, and the copper ions occupy the octahedral sites of the spinel lattice, leading to a structural formula close to $\left(\mathrm{Fe}^{3+}\right)_{\mathrm{A}}\left[\mathrm{Cu}^{2+} \mathrm{Fe}^{3+}\right]_{\mathrm{B}} \mathrm{O}_{4}$, corresponding to the equilibrium distortion at room temperature.

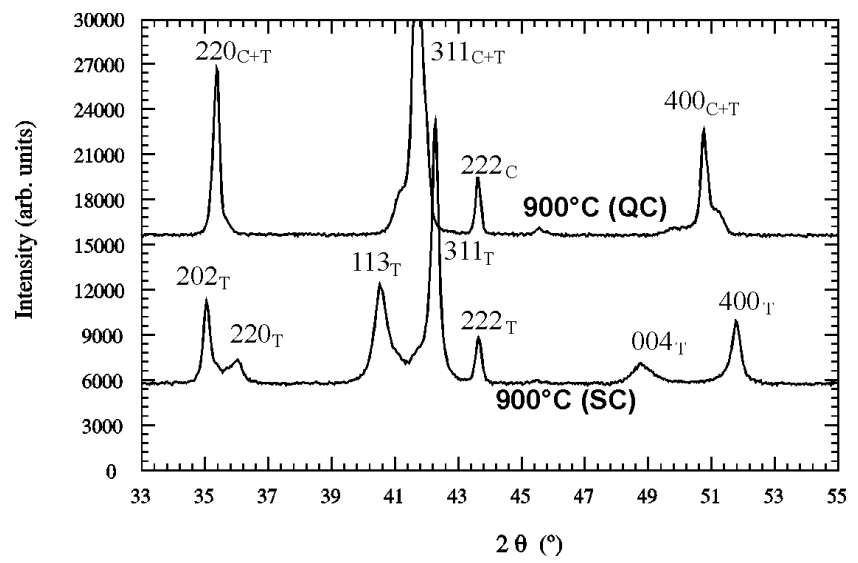

Figure 1. X-ray diffraction patterns of samples $\mathrm{CuFe}_{2} \mathrm{O}_{4}$ obtained by slow cooling (SC) or by rapid quenching in $\mathrm{CO}_{2}(Q C)$, measured at room temperature.

A $\quad$ B

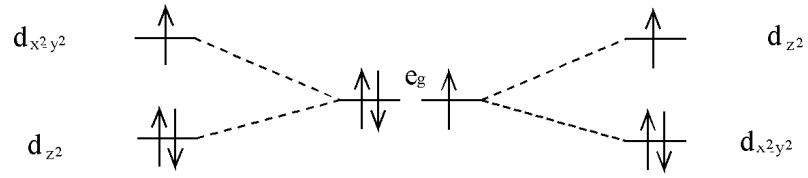

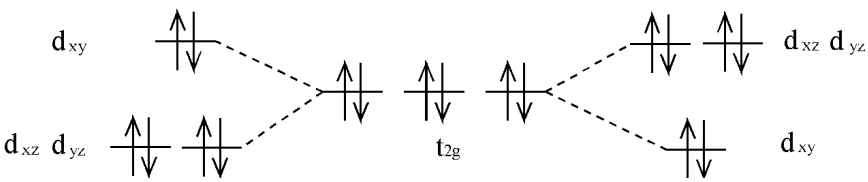

Figure 2. Orbital splitting of the d-energy levels within the cooper ion $\left(d^{9}\right)$ diagram showing the two possible Jahn-Teller distortion in an octahedral complex.

The tetragonal distortion in the $\mathrm{CuFe}_{2} \mathrm{O}_{4}$ compounds is attributed to the cooperative distortion that is driven by the octahedrally coordinated $\mathrm{Cu}^{2+}\left(3 \mathrm{~d}^{9}\right)[2,6,13]$. The electron configu- 
ration of $\mathrm{Cu}^{2+}$ located at octahedral sites is $\left(\mathrm{t}_{2 g}^{6}\right) \mathrm{e}_{g}^{3}$. While six electrons with antiparallely aligned spins occupy the triplet, three electrons on the orbital $\mathrm{e}_{\mathrm{g}}$ can be distributed in two ways (double degenerancy) see figure 2. The first alternative (figure $2 \mathrm{~B}$ ) leads to an axially flattened octahedron $(c / a<1)$; the second one (figure $2 \mathrm{~A})$ causes elongating of the octahedron $(c / a>1)$ e.g., $\mathrm{CuFe}_{2} \mathrm{O}_{4}$.

Investigations of the thermal phase transition of the product formed as a result of slow cooling of copper ferrite sample were carried out at the synchrotron beamline B2 at HASYLAB (DESY, Hamburg).

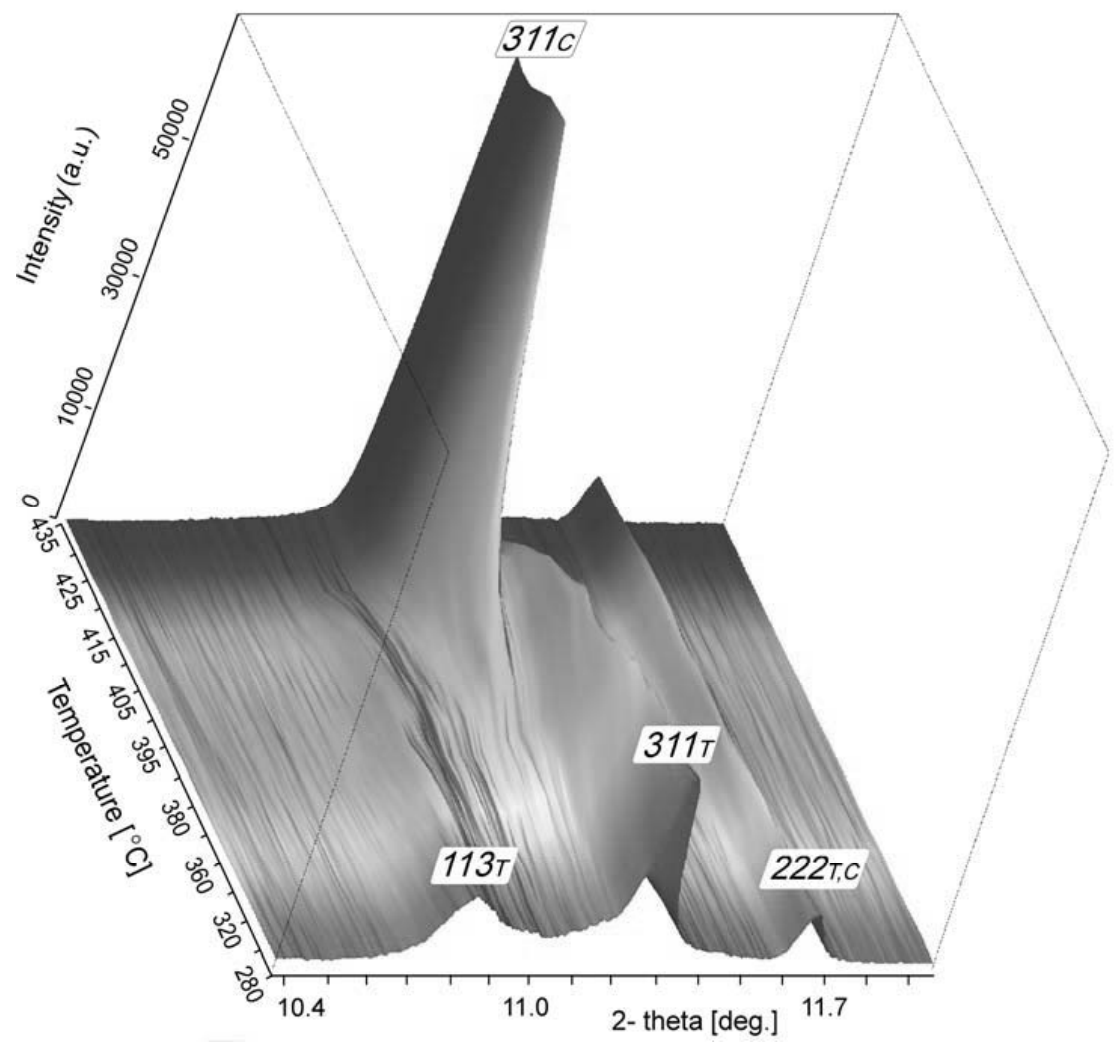

Figure 3. Temperature evolution of the $\mathrm{X}$-ray diffraction patterns for $\mathrm{CuFe}_{2} \mathrm{O}_{4}(\mathrm{SC})$. Data were measured at beamline B2, Synchrotron DESY HASYLAB, Hamburg. The shift of reflections $113_{T}, 311_{T}$ at the tetragonal $\rightarrow$ cubic phase transition can clearly be observed. For the graphic representation the program EVA (DIFFRAC plus BASIC Evaluation Package, Bruker AXS) was used.

The synchrotron powder diffraction scans (figure 3) reveal that the structural phase transition at approximately $\sim 340^{\circ} \mathrm{C}$ to $\sim 420^{\circ} \mathrm{C}$ is manifested by the shift and disappearance of the reflections $113_{\mathrm{T}}, 311_{\mathrm{T}}$ (tetragonally distorted spinel, $F 4_{1} / d d m$ ) and appearance of a new re- 
flection $311_{\mathrm{C}}$ (cubic spinel, $F d \overline{3} \mathrm{~m}$ ) in the investigated temperature range. Evidence is given that above $420^{\circ} \mathrm{C}$ the JT-distortion disappears in the structure.

Annealing treatment can modify the cationic distribution in the spinel lattice. Structural analysis results indicated that above $350^{\circ} \mathrm{C}$ copper ions partially occupy the tetrahedral sites and the structural $\left(F 4_{1} / d d m\right) \rightarrow(F d \overline{3} m)$ phase transition appears. On heating the sample, the copper ions migrate to tetrahedral sites (figure 4A) and the structural formula of the ferrite changes to $\left(\mathrm{Cu}_{\mathrm{x}}{ }^{2+} \mathrm{Fe}_{1-\mathrm{x}}{ }^{3+}\right)_{\mathrm{A}}\left[\mathrm{Cu}_{1-\mathrm{x}}{ }^{2+} \mathrm{Fe}_{1+\mathrm{x}}{ }^{3+}\right]_{\mathrm{B}} \mathrm{O}_{4}$. The resulting decrease in $\mathrm{Cu}^{2+}$ ions in the octahedral sites gives rise to a less distorted crystalline structure. The redistribution $\mathrm{Cu}^{2+}$ ions in the spinel lattice is revealed by the variation of the tetragonal distortion ( $\mathrm{c} / a$ of the unit cell). For the slow cooled sample, the $c / a$ ratio of the tetragonal spinel phase is reported in figure $4 \mathrm{~A}$ as a function of temperature. In this case, the $c / a$ ratio diminishes as the temperature increases up to $415^{\circ} \mathrm{C}$. In particular, $\mathrm{Cu}^{2+}$ intersite cationic migration is also correlated with the decrease in the $c / a$ ratio. More precisely, the migration of $\mathrm{Cu}^{2+}$ ions from octahedral to tetrahedral sites is responsible for this decrease. It has been shown that placed in the octahedral sites $\mathrm{Cu}^{2+}$ ions migrate to the tetrahedral sites. Such migration occurs above $350^{\circ} \mathrm{C}$ (figure 4B).
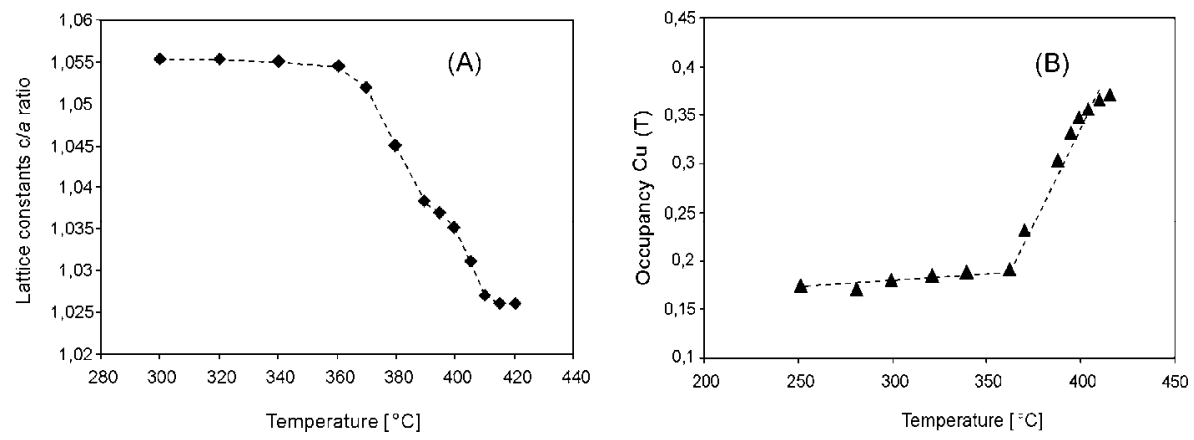

Figure 4. Evolution of the c/a ratio for the tetragonally distorted spinel phase $\mathrm{CuFe}_{2} \mathrm{O}_{4}(\mathrm{SC})$ as a function of temperature $(A)$, and the occupancy of $\mathrm{Cu}^{2+}$ at the spinel tetrahedral sites $(B)$. Dashed lines are guides for the eyes.

\section{Concluding remarks}

Polycrystalline $\mathrm{CuFe}_{2} \mathrm{O}_{4}$ samples have been successfully prepared by a simple combustion method using citrate-nitrate precursors. All the ferrite samples studied were prepared at the same temperatures, but one series was slowly cooled from $900^{\circ} \mathrm{C}$ to room temperature, and another was quenched from $900^{\circ} \mathrm{C}$. The most striking effect observed in this experiment was the dependence of the reaction products on the preparation conditions. The SC and QC sample displayed different thermal behavior. The nature of the structural transition in inverse spinels has been investigated using the synchrotron XRD technique. Slow cooled samples are subjected to order-disorder transformation, due to the migration $\mathrm{Cu}^{2+}$ from octahedral to tetrahedral sites. This phenomenon transforms the tetragonally distorted spinel structure 
$\left(F 4_{1} / d d m\right)$ into a cubic lattice $(F d \overline{3} m)$. The tetragonal $\rightarrow$ cubic phase transition occurs in the temperature range from $\sim 360^{\circ} \mathrm{C}$ to $\sim 420^{\circ} \mathrm{C}$. The resulting cubic lattice cannot be stabilized at room temperature by quenching. Annealing can modify the cationic distribution in spinel lattice - it has been shown that placed in the octahedral sites $\mathrm{Cu}$ ions migrate to the tetrahedral positions. The resulting decrease in copper ions in the octahedral sublattice gives rise to a less distorted crystalline structure, and above $420^{\circ} \mathrm{C}$ the structural JT-distortion disappears.

\section{References}

1. Selvan, R. K., Krisham V., Augustin, Ch.O., Bertagnolli, H., Kim, Ch.S. \& Gedanken, A., 2008, Chem. Mater., 20, 429.

2. Tang, X.X., Manthiram, A. \& Goodenough, J.B., 1989, J. Solid State Chem., 79, 250.

3. Villette, C., Tailhades, Ph. \& Rousset, A., 1995, J. Solid State Chem., 117, 64.

4. Gajbhiye, N.S., Balaji, G., Bhattacharyya S. \& Ghafari, M., 2004, Hyperfine Interact., 156-157, 57.

5. Ohnishi, H. \& Teranishi, T., 1961, J. Phys. Soc. Jpn., 16, 35.

6. Ata-Allah, S.S., 2004, J. Solid State Chem., 177, 4443.

7. d'Huysser, A., Lerebours-Hannoyer, R., Lenglet, M. \& Bonnelle, J.P., 1981, J. Solid State Chem., 39, 246.

8. Desai, M., Prasad, S., Venkataramani, N., Samajdar, I., Nigam, A.K. \& Krishnan, R., 2002, J. Appl. Phys., 91, 2220.

9. Desai, M., Prasad, S., Venkataramani, N., Samajdar, I., Nigam, A.K. \& Krishnan, R., 2002, J. Magn. Magn. Mater., 246, 266.

10. Verma, S. \& Joy, P.A., 2008, Mater. Res. Bull. in press, doi: 10.1016/j.materresbull.2008.01.023.

11. Rodriguez-Carvajal, J., 2001, Newslett. IUCr Commission Powd. Diffr., 26, 12.

12. Tailhades, Ph., Villette, C., Rousset, A., Kulkarni, G.U., Kannan, K.R., Rao, C.N.R. \& Lenglet, M., 1998, J. Solid State Chem., 141, 56.

13. Falvello, L.R., 1997, J. Chem. Soc., Dalton Trans., 23, 4463.

Acknowledgements. The synchrotron measurements at DESY-HASYLAB were supported by the IA-SFS-Contract No. RII3-CT-2004-506008 of European Commission. The author would like to thank Dr. D. Trots from Hasylab, for his assistance during experiments. 